\title{
SPATIOTEMPORAL CHANGES IN DAILY MAXIMUM AND MINIMUM TEMPERATURES AND THEIR RELATIONS WITH A LARGE-SCALE ATMOSPHERIC CIRCULATION PATTERN: A CASE STUDY IN THE WEI RIVER BASIN, CHINA
}

\author{
HUANG, S. Z. $.^{1,2^{*}}-$ LI, P. ${ }^{2}-$ HUANG, Q. ${ }^{2}$ \\ ${ }^{1}$ State Key Laboratory of Simulation and Regulation of Water Cycle in River Basin \\ China Institute of Water Resources and Hydropower Research, Beijing 100038, China \\ ${ }^{2}$ State Key Laboratory of Eco-hydraulics in Northwest Arid Region of China, Xi'an University \\ of Technology, Xi'an 710048, China \\ (phone: +86-29-8231-2801; fax: +86-29-8231-2797) \\ *Corresponding author \\ e-mail: huangshengzhi7788@126.com; phone: +86-29-8231-2801; fax: +86-29-8231-2797
}

(Received $27^{\text {th }}$ Sep 2019; accepted $4^{\text {th }}$ Feb 2020)

\begin{abstract}
The long-term mean air temperature has increased with continued greenhouse-gas emissions in the past decades in the Wei River Basin (WRB) (China), with little understanding of the changes in extreme temperatures. In this study, the change characteristics of both maximum (Tmax) and minimum (Tmin) temperatures at daily, monthly, and annual scales were fully examined, and their relations with the Arctic Oscillation (AO) were also explored. The modified Mann-Kendall trend test method (MMK) and heuristic segmentation method were employed to detect the trends and change points of the Tmax and Tmin at multiple scales, respectively. Subsequently, the cross wavelet transform was adopted to reveal the correlations between Tmax/Tmin and AO. Results indicated: (1) both monthly and annual Tmax and Tmin showed significantly increasing trends, whilst at daily scale they generally exhibited no obvious trends; (2) change points were found in monthly, seasonal, and annual Tmax and Tmin, implying that the stationarity of Tmax and Tmin series in the WRB has been ineffective; (3) AO had strong impacts on Tmax and Tmin changes in the WRB. Our results highlight the asymmetric response of Tmax and Tmin at the monthly, seasonal, and annual scales, which has great implications for ecosystem functions and agricultural production.
\end{abstract}

Keywords: temperature extremes, Arctic Oscillation, the heuristic segmentation method, the cross wavelet transform, the Wei River Basin

\section{Introduction}

The Fifth Assessment Report of the Intergovernmental Panel on Climate Change (IPCC, 2007) has stated that global average temperature has risen by nearly $0.85^{\circ} \mathrm{C}$ (IPCC, 2013) within the 1880-2012 period. Regionally, China has warmed by $0.45 \pm 0.05^{\circ} \mathrm{C}$ during 1860-2005 (CMA, 2006). Accompanying increased surface air temperature are the enhanced evaporation demand (Leng et al., 2015a), accelerated global hydrologic cycle (Menzel et al., 2002; Wang et al., 2013; Huang et al., 2016, 2017; Han et al., 2019; Fang et al., 2019a), and the increase of extreme events (WMO, 2003; Guo et al., 2013, 2019a,b; Leng et al., 2015b,c; Zhao et al., 2019a; Dai et al., 2020; Guo et al., 2020). Compared to the variations of mean conditions, variations of extremes can exert more adverse influences on both the natural environment and human society (Easterling et al., 2000a; Patz et al., 2005; Kapsomenakis et al., 2013; Zhao et al., 2019) and have attracted much attention during the last decades (Beniston et al., 2004; Lehner 
et al., 2006; Piao et al., 2010; Sheffield et al., 2012; Fang et al., 2019b; Zhao et al., 2019b; Ren et al., 2020).

Although many researchers have investigated the spatial and temporal changes in temperature extremes (Kunkel et al., 1999; Easterling et al., 2000b; Nasrallah et al., 2004; Fuhrer et al., 2006), the changing characteristics of temperature extremes vary regionally, showing obvious changes in some areas and no striking trends in other areas (Bonsal et al., 2001).

As for a time series, change point is a vital change characteristic. The statistical characteristics of a specific time series before a change point differ significantly from those after the change point. If a change point is found, it indicates the time series is not stationary and is characterized by a noticeable variation. Change point is a time when the temporal pattern of a time series changes significantly. Detection of change points in hydrological series is highly important not only for understanding the location and timing when there is a change in the factors driving the complex system, but also helps us make inference about the issue of non-stationarity (Li et al., 2020; Zhao et al., 2020a, b). Indeed, if the issue of non-stationarity in a hydrological time sequence exists, the conventional hydrological frequency analysis assuming the stationarity of time sequence would be useless in practice (Milly et al., 2008; Vogel et al., 2011; Gilroy et al., 2012). Many previous studies concerning temperature extremes focused on their trend variations, few of them paid attention to their change point detection. In view of the importance of identifying change points for a specific time series, the investigation on identifying change points in maximum (Tmax) and minimum (Tmin) temperatures series was conducted in this study.

Furthermore, majority of previous studies on temperature extremes paid attention to the spatial and temporal variations of Tmax and Tmin series, rare studies explained detected changes. Indeed, understanding of the cause of Tmax and Tmin series changes is extremely important, which helps better understand climate change. Therefore, this study attempts to reveal the possible relations between temperature extremes and the Arctic Oscillation (AO). AO is an important pattern of climate change in the Northern Hemisphere and has been shown to exert strong influences on the climate change in the middle and high latitude areas (Toreti et al., 2010; Wang et al., 2013). The meteorological and hydrological processes may show various characteristics at different spatial scales (Tudesquea et al., 2014). In order to fully reveal the scale effect on the correlations between temperature extremes and AO, the response of temperature extremes to $\mathrm{AO}$ at different spatial scales was also explored in this study.

Here, the Wei River Basin (WRB) is chosen as a case study. The WRB is located in a typical climatic zone (monsoon region) (Huang et al., 2014a). Tmax and Tmin series have been reported to exert strong adverse influences on both agricultural production and runoff variations. Investigation of the spatio-temporal changes in temperature extremes in the WRB can help to understand and effectively guide local water resources management in a changing climate. We focus on the temperature extremes at multiple time scales, i.e. daily, monthly, and annual Tmax and Tmin series. The major objectives of this study are: (1) to reveal the spatial and temporal variations of Tmax/Tmin; (2) to detect the change points in Tmax/Tmin series at different timescales in the WRB; (3) to analyze the possible relations between Tmax/Tmin and the AO series at different spatial scales. 


\section{Materials and Methods}

\section{Introduction of the WRB}

The WRB was selected as the study area in this study. It was partitioned into eight sub-basins based on the secondary basin boundary in China, and their zone ID are 26, 28, 29, 31, 33, 36, 40, and 41, respectively (Figure 1). Situated in a continental monsoon climate-impacted zone, the region is characterized by rich precipitation and high temperature in summer, and dominated by rare precipitation and low temperature in winter. Its annual precipitation is nearly $559 \mathrm{~mm}$ (Zhang et al., 2008; Liu et al., 2018a). The precipitation in the WRB varies obviously at seasonal scale, with flood season (from June to September) precipitation accounting for roughly $60 \%$ of the annual average (Huang et al., 2020).

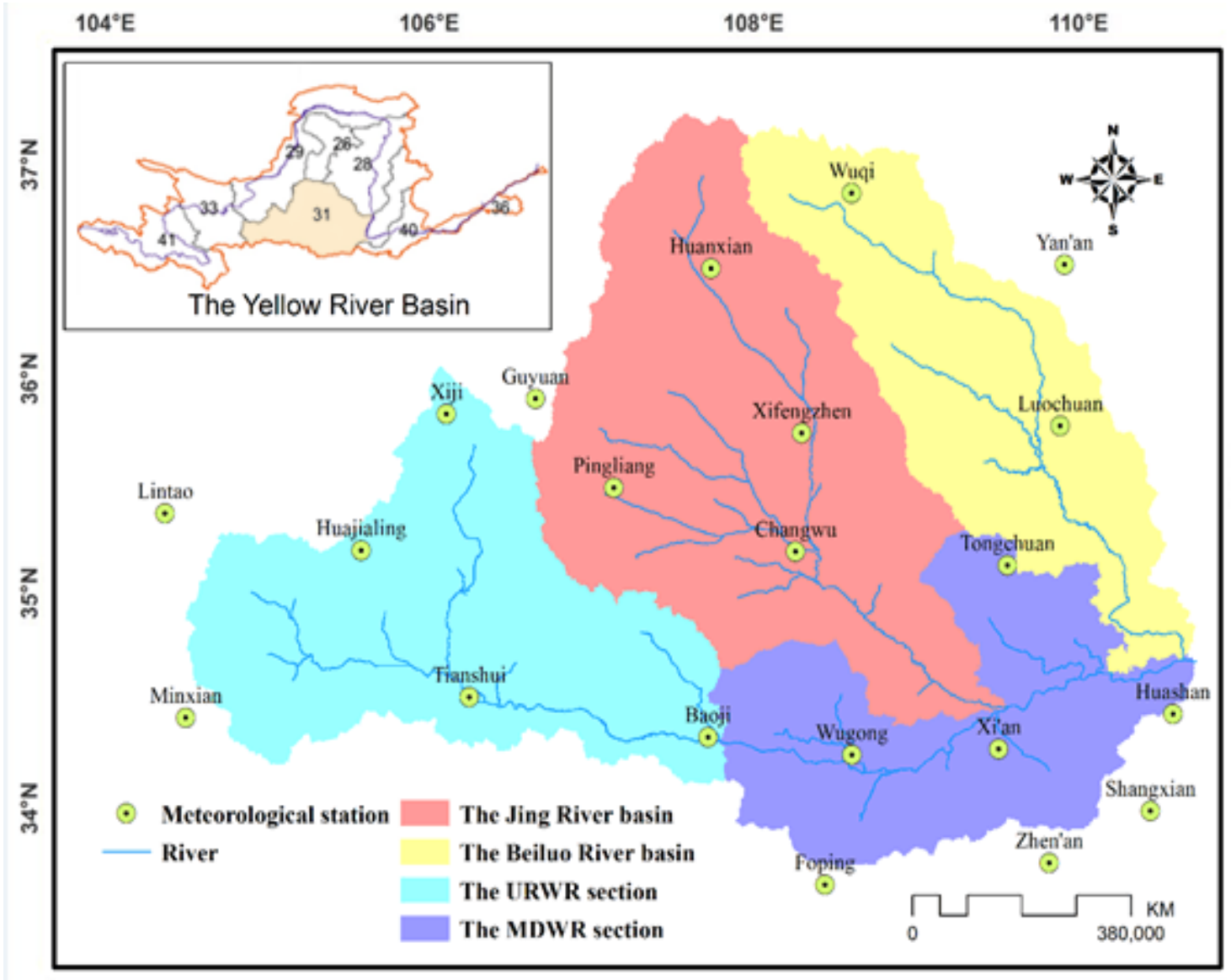

Figure 1. Location of the WRB and related meteorological stations in the Yellow River Basin, China

In order to explore the changing characteristics of temperature extremes and their correlation with $\mathrm{AO}$ at various spatial scales, the WRB was divided into four sub-basins primarily based on the distribution characteristic of its river system. The four sub-basins are the upper reaches of the Wei River (URWR) section, the middle and downstream of the Wei River (MDWR) section, the Jing River basin, and the Beiluo River basin (Figure 1). 


$$
-3280-
$$

\section{Data}

Daily minimum and maximum air temperature are collected from 21 meteorological stations located in the WRB (Figure 1). The dataset is obtained from the National Climate Center (NCC) of the China Meteorological Administration (CMA), and are homogenized before their release. Note that monthly Tmax/Tmin was determined by the largest/lowest daily data in a month, and annual Tmax/Tmin was determined by the largest/lowest monthly data in a year. The sub-basin Tmax and Tmin are determined from point Tmax and Tmin based via calculating the arithmetic mean value of point Tmax and Tmin. The detailed information of these stations is summarized in Table 1. Each station has daily maximum and minimum temperature records spanning January $1^{\text {st }}, 1958$-December $31^{\text {st }}$, 2008. These data have been successfully applied in our previous studies (Huang et al., $2014 \mathrm{~b}, \mathrm{c}$ ) in investigating drought evolution characteristics in the WRB. Additionally, the monthly AO series within 1958-2008 was obtained from the National Oceanic and Atmospheric Administration (NOAA).

Table 1. Information on meteorological stations analyzed in this study

\begin{tabular}{c|c|c|c|c|c}
\hline Station name & Sub-basin & Station No. & Longitude (E) & Latitude (N) & Elevation (m) \\
\hline Lintao & URWR & 1 & 103.85 & 35.35 & 1893.8 \\
Minxian & URWR & 2 & 104.02 & 34.04 & 2315 \\
Huajialing & URWR & 3 & 105.00 & 35.38 & 2450.6 \\
Xiji & URWR & 4 & 105.72 & 35.97 & 1916.5 \\
Tianshui & URWR & 5 & 105.75 & 34.58 & 1141.7 \\
Guyuan & JRB & 6 & 106.27 & 36.00 & 1753 \\
Pingliang & JRB & 7 & 106.67 & 35.55 & 1346.6 \\
Baoji & URWR & 8 & 107.13 & 34.35 & 612.4 \\
Huanxian & JRB & 9 & 107.30 & 36.58 & 1255.6 \\
Xifengzhen & JRB & 10 & 107.63 & 35.73 & 1421 \\
Changwu & JRB & 11 & 107.80 & 35.20 & 1206.5 \\
Foping & MDWR & 12 & 107.98 & 33.52 & 827.2 \\
Wuqi & BL & 13 & 108.17 & 36.92 & 1331.4 \\
Wugong & MDWR & 14 & 108.22 & 34.25 & 447.8 \\
Xi'an & MDWR & 15 & 108.93 & 34.30 & 397.5 \\
Tongchuan & MDWR & 16 & 109.07 & 35.08 & 978.9 \\
Zhen'an & MDWR & 17 & 109.15 & 33.43 & 693.7 \\
Yan'an & BL & 18 & 109.50 & 36.60 & 958.5 \\
Luochuan & BL & 19 & 109.50 & 35.82 & 1159.8 \\
Shangxian & MDWR & 20 & 109.97 & 33.87 & 742.2 \\
Huashan & MDWR & 21 & 110.08 & 34.48 & 2064.9 \\
\hline
\end{tabular}

URWR, MDWR, JRB and BL denote the upper reaches of the Wei River, middle and downstream of the Wei River, Jing River basin and Beiluo River basin, respectively

\section{Methodology}

\section{The modified Mann-Kendall trend test method}

Given initial Mann-Kendall (MK) trend test method is easily influenced by the persistence of hydro-meteorological series, Hamed and Rao (1998) proposed a modified MK (MMK) trend test method to remove the persistence through taking into account the lag-i autocorrelation. Daufresne et al. (2009) found that the MMK is more robust than MK in terms of examining the trends of hydro-meteorological series. Given the weakness of the MK mentioned above, the MMK trend test method was employed to in this study to calculate the change trends of Tmax/Tmin in the WRB. The detailed computation processes can be referred to Huang et al. (2014a, b). 


\section{The heuristic segmentation method}

Generally, traditional statistical test methods such as the sliding T test, rank sum test, sliding $\mathrm{F}$ test, and Mann-Kendell test are frequently adopted to detect change points, assuming the time series of interest is linear and stationary. Nevertheless, extreme temperature time series is extremely nonlinear owing to the high variability caused by many factors. Hence, it is difficult for them to obtain the real change points accurately. To this end, the heuristic segmentation method which was proposed by Pedro et al. (2001) was adopted to capture the change points in temperature extremes series in this study. The method is based on the sliding $\mathrm{T}$ test and further modified, which can be applied to identify the change points in highly nonlinear and nonstationary time series. The detailed calculation processes can be referred to Huang et al. (2017) and Liu et al. (2019).

\section{The cross wavelet transform}

The cross wavelet transform proposed by Hudgins et al. (1993) is a new technique in revealing the correlation between two-time series of interest. It is featured with combining the cross spectrum analysis with wavelet transform, and can reveal the changing features and the coupled oscillations of two-time series of interest in both time and frequency domains (Hudgins et al., 1996; Torrence et al., 1998). Hence, it was applied in this study to examine the correlation between Tmax/Tmin in the WRB and AO. The detailed calculation processes can be referred to Huang et al. (2018).

\section{Results}

\section{Spatial and temporal changes in Tmax and Tmin}

In order to vividly present the spatial change characteristics of Tmax and Tmin in the WRB, the stations adopted in this study were ranked according to the magnitude of their longitudes. Additionally, the MMK statistics of Tmax and Tmin in each month during 1958-2008 in the WRB were calculated, which were plotted in Figure 2 and Figure 3, respectively, with $x$ axis of station number ranked according to the magnitude of their longitudes and $y$ axis of the MMK statistics of Tmax and Tmin in each month. A positive value of MMK statistics represents an increasing trend of Tmax/Tmin series, especially for the value is larger than 1.96, indicating a statistically significant increasing trend at the $95 \%$ confidence level. Otherwise, the detection trend is no obvious, and vice versa. Hence, the spatial and temporal changes in Tmax and Tmin at the monthly scale can be displayed in Figure 2 and Figure 3, respectively.

Spatially, in the western and middle basin (Figure 2), increase of monthly Tmax is found for almost all months, especially for station 9 where significantly increasing trend is detected in February, April, June, and July. Changes in Tmax in the eastern basin is a little complex with decreasing trends in summer (June, July, and August) and increasing trends in Spring (February, march, April). The change pattern is especially evident for station 17, in which Tmax decreased significantly in June, but increased significantly in January, February, March, October, November, and December. Generally, changes in Tmax at the monthly scale exhibited a noticeable spatial difference. Temporally, the MMK of Tmax series is dominated by positive values in February, April and summer (June, July, and August), indicating a statistically increasing trend. Particularly, February and April show significant increasing trend. In contrast, the Tmax series for January, March, May, November, and December generally have decreasing trends. 

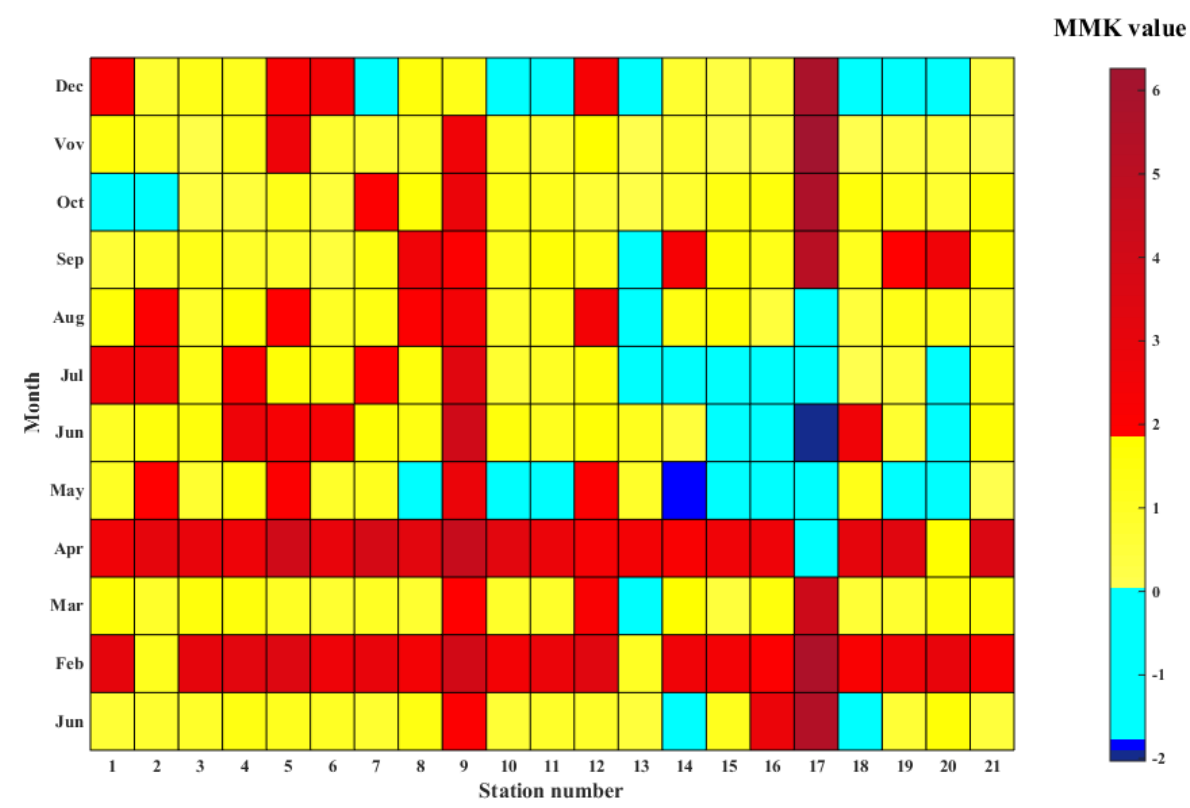

Figure 2. The change trends of monthly maximum temperature in the WRB (Red, dark blue, yellow and sky blue represent significant increasing, significant decreasing, no obvious increasing and no obvious decreasing trends, respectively)

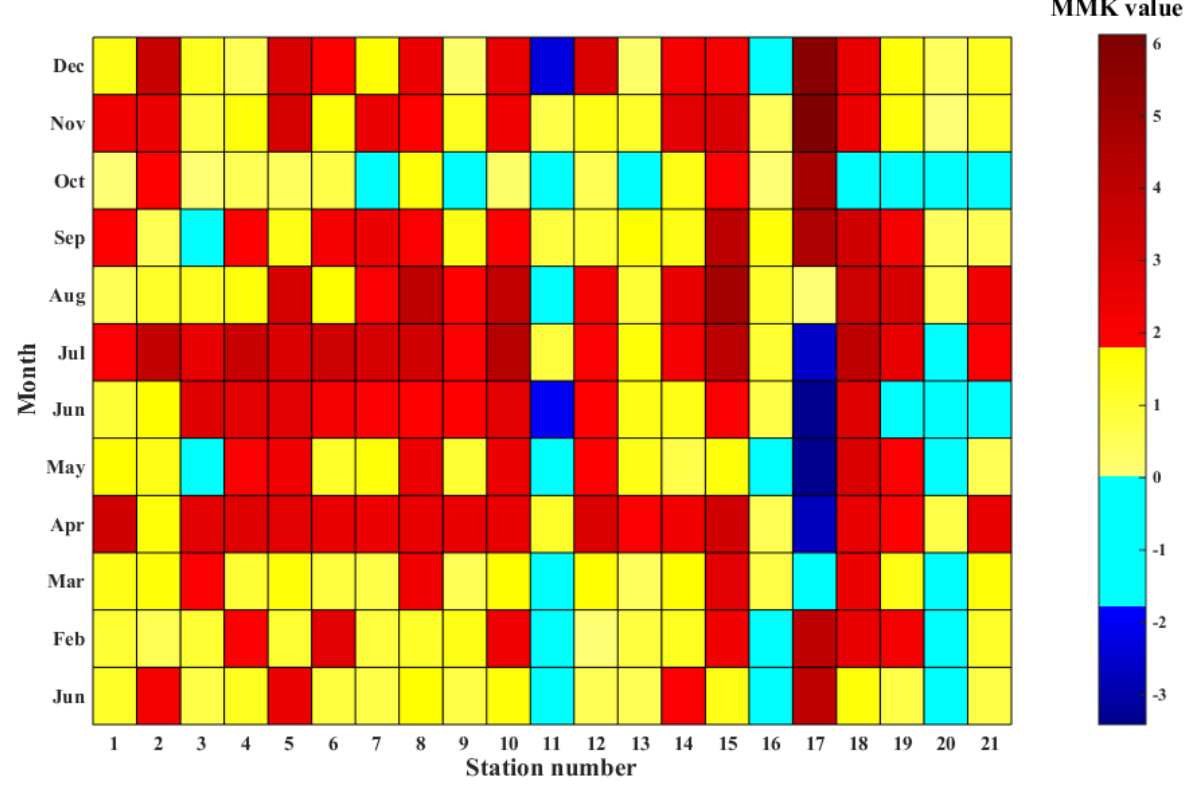

Figure 3. The change trends of monthly minimum temperature in the WRB

As for the changes in Tmin (Figure 3), spatially, being similar to the changes in Tmax, the western and middle basin is mainly characterized by increasing Tmin in almost all months except for station 11 experiencing decrease in January, February, March, May, June, October and December. In general, the eastern basin is characterized by increasing Tmin except for stations 17 and 20. Note that the Tmax and Tmin at station 17 have a significantly increasing trend at the $99 \%$ confidence level in autumn and winter and a significantly decreasing trend 
at the $99 \%$ confidence level in summer. The cause may be related to its location near to the edge of monsoon region compared with other meteorological stations, its temperature extremes therefore are easily impacted by the changing global climate (Huang et al., 2014c). The underlying causes of the strange behavior of station 17 need to be further investigated in the future study. Temporally, a statistical increase is detected in almost all months in most of the basin. In particular, April, June and July are dominated by significant increasing trends. In contrast, only October showed no obvious decreasing trends.

Overall, the spatial and temporal change patterns of Tmin are similar to that of Tmax. The MMK statistic of the diurnal temperature range in the whole basin is 0.16 , which exhibits no obvious trend. The normalized annual Tmax and Tmin series during 1958-2008 in the four sub-basins are illustrated in Figure 4, which is based on the Eq.1. Note that the sub-basin Tmax and Tmin are determined from point Tmax and Tmin via calculating the arithmetic mean value of point Tmax and Tmin. It can be found that all of the sub-basins are characterized by increasing annual Tmax and Tmin. The MMK statistics of annual Tmax in the four sub-basins are 3.88, 4.51, 3.91 and 2.36, respectively, whilst those of annual Tmin are 5.11, 4.54, 3.64 and 3.89, respectively. The increase in annual Tmin is faster than that of annual Tmax in these sub-basins except for the Jing River basin.

$$
\frac{x-x_{\min }}{x_{\max }-x_{\min }}
$$
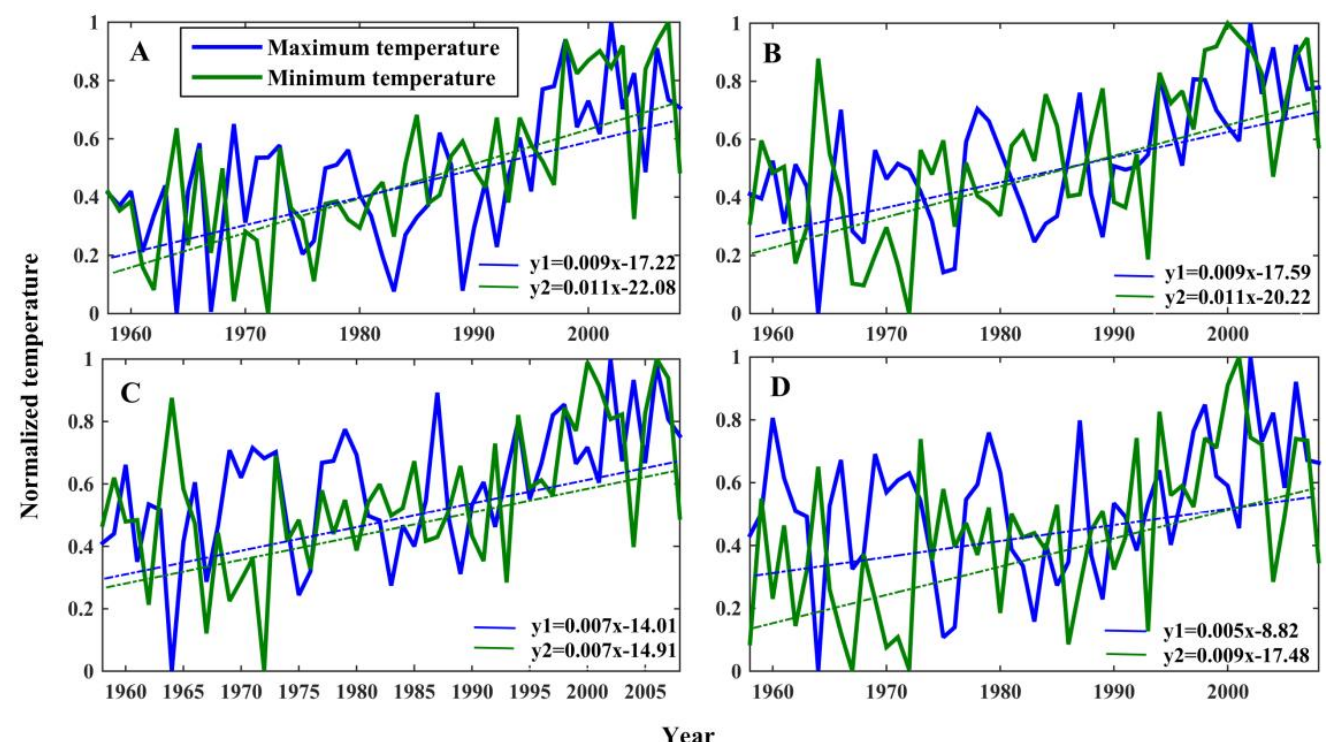

Figure 4. The normalized annual maximum and minimum temperature series during 1958-2008 in the four sub-basins. A, B, C and D denote the URWB section, the MDWR section, the Jing River basin and the Beiluo River basin, respectively

The MMK statistics of daily Tmax and Tmin were also calculated in this study, and the spatial and temporal distribution of daily Tmax and Tmin in the WRB is presented in Figure 5. It can be found that the MMK statistics of daily Tmax at all the stations are positive, and those at stations 2, 5, 12, and 17 are significant at the 95\% confidence level (Figure 5A). Similarly, most of the MMK statistics of daily Tmin at all the stations are positive, and those at stations 5, 
10, 15, and 18 are significant at the $95 \%$ confidence level (Figure 5B). Differently, it also has a significant decreasing trend at stations 11 and 20 (Figure 5B).
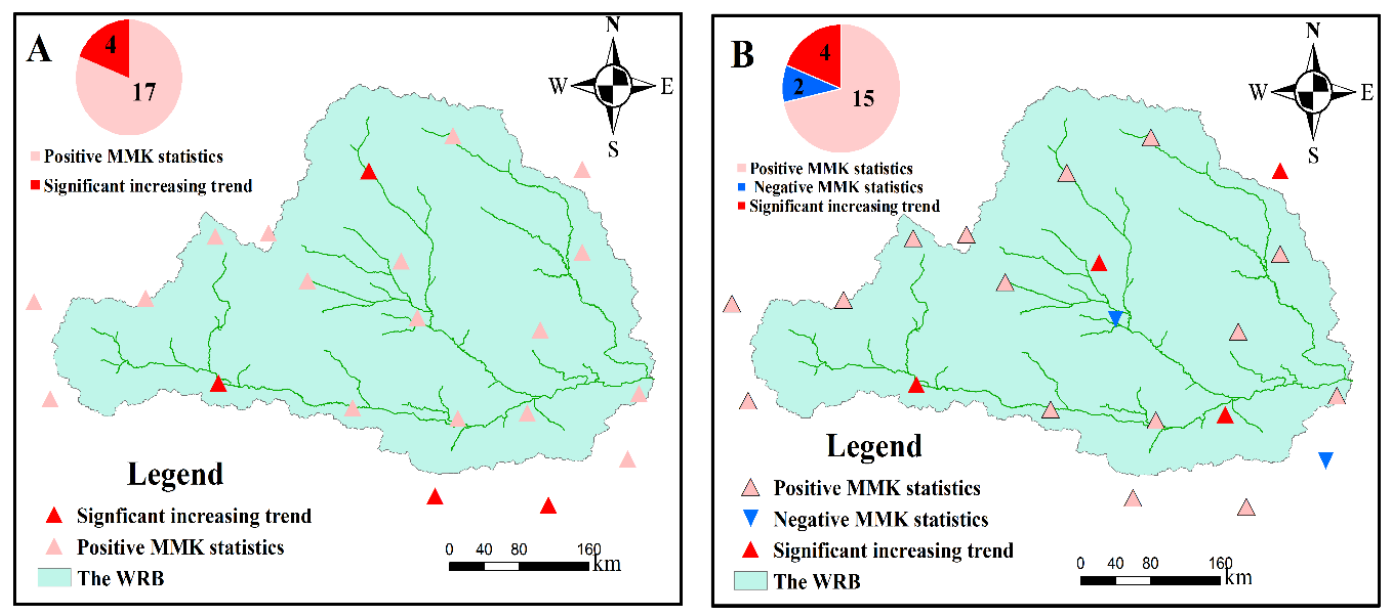

Figure 5. The spatial and temporal distribution of daily Tmax (A) and Tmin (B) in the WRB

\section{Identification of change points of Tmax/Tmin and $A O$ index series}

The heuristic segmentation method introduced in previous was adopted to identify change points of Tmax and Tmin in the four sub-basins. The threshold $P_{0}$ was set to 0.95 and $l_{0}$ was set to 25. The segmentations and identified change points of the annual Tmax and Tmin in the four sub-basins are exhibited in Figure 6 and Figure 7, respectively.

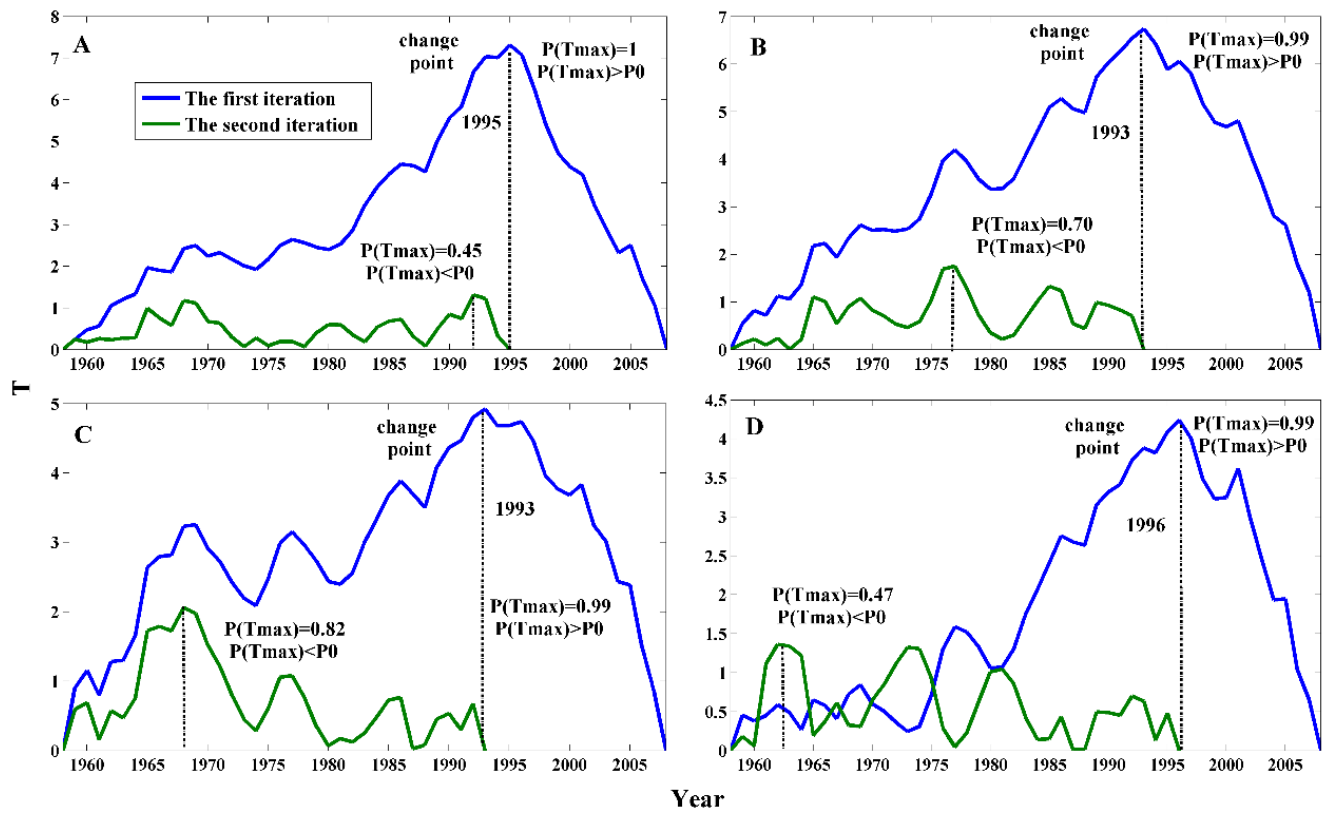

Figure 6. Segmentations and identified change points of annual maximum temperature in the $W R B$. A, B, C and D denote the URWB section, the MDWR section, the Jing River basin and the Beiluo River basin, respectively 


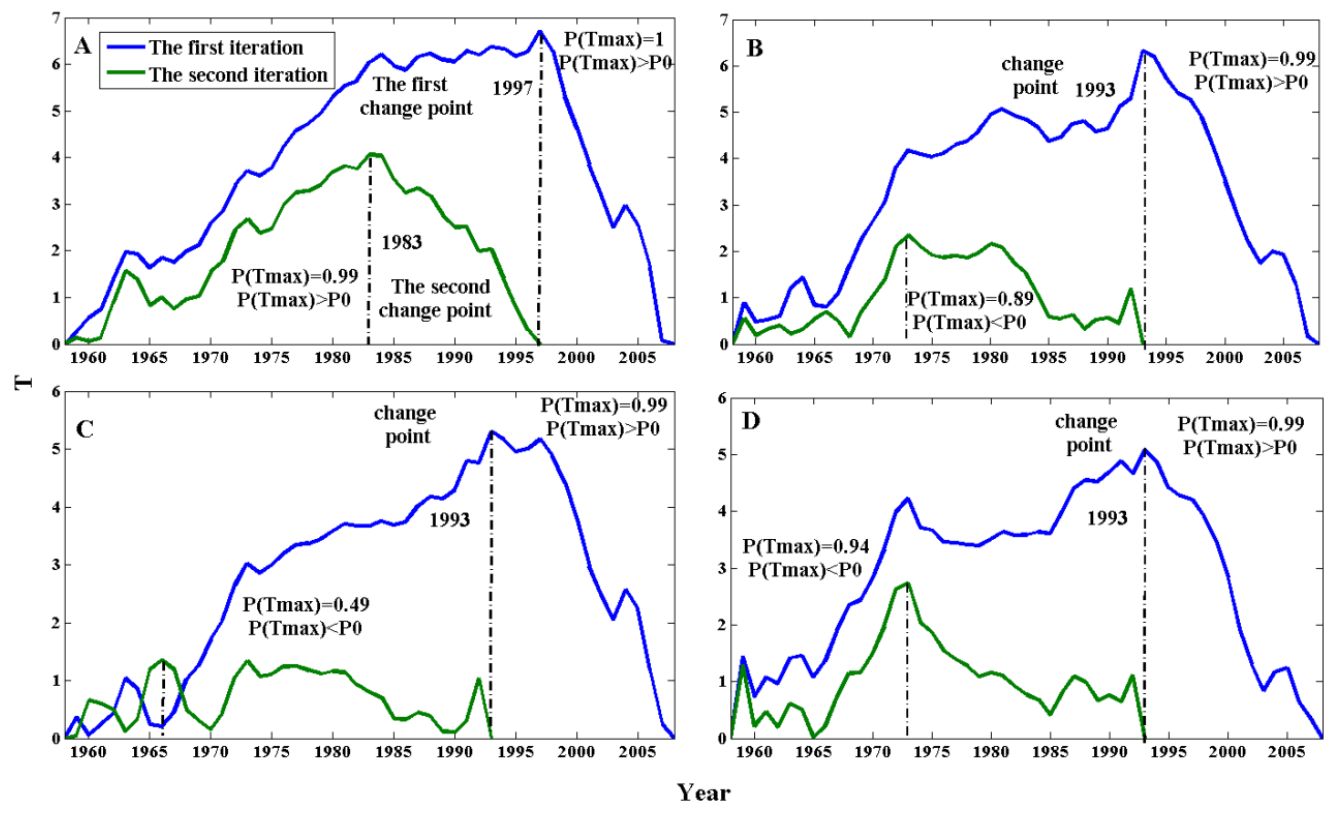

Figure 7. Segmentations and identified change points of annual minimum temperature in the WRB. A, B, C and D denote the URWB section, the MDWR section, the Jing River basin and the Beiluo River basin, respectively

In general, both of annual Tmax and Tmin series have change points, implying that the stationarity of temperature extremes in the WRB is invalid. As shown in Figure 6A, a change point of 1993 in Tmax was identified in the URWB section in the first iteration due to the condition that $P\left(t_{\max }\right)=1>P_{0}$, while no change point was detected in the second iteration due to the condition that $P\left(t_{\max }\right)=0.45<P_{0}$. For the MDWR section and the Jing River basin, a common change point (1993) was found in the first iteration due to the condition that $P\left(t_{\max }\right)>P_{0}$, while no change point was detected in the second iteration due to the condition that $P\left(t_{\max }\right)<P_{0}$. For the Beiluo River basin, a change point of 1996 was detected in the first iteration, whilst no change point was found in the second iteration. From Figure 7A, it can be found that a change point of 1997 was detected for the annual Tmin series in the URWB section. For the Tmin in the MDWR section, Jing River basin, and Beiluo River basin, a change point of 1993 was detected.

Moreover, the change points of monthly and seasonal Tmax in the four sub-basins in the WRB were also identified, and their results are displayed in Table 2 and Table 3. It can be found that the change points of monthly Tmax in the four sub-basins vary from 1967 to 2003 with a striking variation (Table 2). Note that the monthly Tmax in May in the four sub-basins has no change point. As for the seasonal Tmax in the four sub-basins, their change points are concentrated in 1990s (Table 2). In general, the change points of the monthly and seasonal Tmax in the Beiluo River basin are less than those in the other sub-basins. The monthly Tmin in November and December in the four sub-basins has no change point (Table 3). Comparatively, the change points of the monthly and seasonal Tmin are less than those of the monthly and seasonal Tmax in the four sub-basins (Table 3). Similarly, the change points of the monthly and seasonal Tmin in the Beiluo River basin are less than those in the other sub-basins. Since the change points of monthly, seasonal, and annual Tmax and Tmin were found, the stationarity of temperature extremes in the WRB is ineffective. 
Table 2. Identification of the change points of monthly and seasonal Tmax in the four subbasins in the WRB

\begin{tabular}{c|c|c|c|c|c|c|c|c|c|c|c|c|c|c|c|c}
\hline Sub-basins & $\mathbf{1}$ & $\mathbf{2}$ & $\mathbf{3}$ & $\mathbf{4}$ & $\mathbf{5}$ & $\mathbf{6}$ & $\mathbf{7}$ & $\mathbf{8}$ & $\mathbf{9}$ & $\mathbf{1 0}$ & $\mathbf{1 1}$ & $\mathbf{1 2}$ & $\mathbf{S p}$ & $\mathbf{S m}$ & $\mathbf{A m}$ & $\mathbf{W t}$ \\
\hline URWR section & 98 & - & $99 / 74$ & 91 & - & 94 & 96 & - & 90 & - & 86 & - & 99 & 95 & 93 & 95 \\
JRB & - & - & 99 & 01 & - & 03 & 94 & - & 86 & - & 86 & 68 & 99 & 96 & 86 & - \\
MDWR section & 69 & 73 & 97 & 91 & - & $67 / 03$ & $68 / 94$ & 68 & 93 & 76 & $89 / 68$ & 68 & 99 & $68 / 93$ & 90 & $69 / 77$ \\
BL & - & - & 99 & 03 & - & - & 94 & - & 86 & - & - & - & 99 & 96 & 86 & - \\
\hline
\end{tabular}

$1,2, \ldots$, and 12 denote January, February,..., and December, respectively; Sp, Sm, Am, and Wt denote spring, summer, autumn, and winter, respectively

Table 3. Identification of the change points of monthly and seasonal Tmin in the four subbasins in the WRB

\begin{tabular}{c|c|c|c|c|c|c|c|c|c|c|c|c|c|c|c|c}
\hline Sub-basins & $\mathbf{1}$ & $\mathbf{2}$ & $\mathbf{3}$ & $\mathbf{4}$ & $\mathbf{5}$ & $\mathbf{6}$ & $\mathbf{7}$ & $\mathbf{8}$ & $\mathbf{9}$ & $\mathbf{1 0}$ & $\mathbf{1 1}$ & $\mathbf{1 2}$ & $\mathbf{S p}$ & $\mathbf{S m}$ & $\mathbf{A m}$ & $\mathbf{W t}$ \\
\hline URWR section & - & $81 / 07$ & - & - & 96 & 97 & 93 & 93 & 73 & - & - & - & 96 & $61 / 93$ & 97 & 85 \\
JRB & - & - & - & 83 & 96 & 97 & 93 & 74 & 68 & - & - & - & 96 & 93 & - & - \\
MDWR section & 69 & 70 & 69 & 81 & 95 & $68 / 93$ & $68 / 92$ & 68 & - & - & - & 68 & $73 / 96$ & $68 / 93$ & - & 70 \\
BL & 72 & - & - & 80 & 96 & 84 & 92 & - & - & - & - & - & - & 90 & 97 & - \\
\hline
\end{tabular}

In addition, identification of the change points of monthly and seasonal AO index was also conducted based on the heuristic segmentation method. Related results are displayed in Table 4. In general, from the monthly perspective, there are change points identified in January, February, May, July, August, September, November, and December. However, from the seasonal perspective, change points are detected in four seasons, indicating that the stationarity of AO status is also ineffective. Through comparison between the change points of Tmax/Tmin and AO, it can be observed that there is no solid linkage between Tmax/Tmin and $\mathrm{AO}$ at monthly and seasonal time scales.

Table 4. Identification of the change points of monthly and seasonal AO index

\begin{tabular}{c|c|c|c|c|c|c|c|c|c|c|c|c|c|c|c|c}
\hline $\mathbf{M} / \mathbf{S}$ & $\mathbf{1}$ & $\mathbf{2}$ & $\mathbf{3}$ & $\mathbf{4}$ & $\mathbf{5}$ & $\mathbf{6}$ & $\mathbf{7}$ & $\mathbf{8}$ & $\mathbf{9}$ & $\mathbf{1 0}$ & $\mathbf{1 1}$ & $\mathbf{1 2}$ & $\mathbf{S p}$ & $\mathbf{S m}$ & $\mathbf{A m}$ & $\mathbf{W t}$ \\
\hline Change points & 82 & 88 & - & - & 07 & - & 73 & 70 & 03 & - & 69 & 70 & 67 & 70 & 71 & 87 \\
\hline
\end{tabular}

$\mathrm{M}$ and $\mathrm{S}$ denote month and season, respectively

Tmax and Tmin variations are associated with the large-scale atmospheric circulations (Liang et al., 2014), underlying surface conditions ( $\mathrm{Yu}$ and Li, 2015), as well as human activities such as carbon dioxide emissions (Pereira et al., 2013). To further explain the phenomenon in a quantitatively way is out of the scope of this study, since the major objective of this paper is to investigate the spatial and temporal variations of maximum and minimum temperature at various spatial and temporal scales, along with exploring the correlation between temperature extremes with the AO series. Therefore, the detailed reasons for the occurrence of the change points in annual maximum and minimum temperature series will be investigated in the future study. 


$$
-3287 \text { - }
$$

\section{The linkages between temperature extremes and $A O$}

As mentioned above, temperature extremes are associated with the large-scale atmospheric circulations (Liang et al., 2014), underlying land surface conditions ( $\mathrm{Yu}$ and Li, 2015), as well as human activities such as carbon dioxide emissions (Pereira et al., 2013). To quantitatively separate the changes in Tmax and Tmin from various large-scale and local scale factors is important but not within the scope of this study. Arctic Oscillation (AO) is found to be closely associated with the climate variations in middle and high latitudes regions (Toreti, 2010; Wang, 2013). Hence, we attempt to examine the possible relations between AO and Tmax/Tmin variations. We focus the analysis on summer and winter seasons. The AO values corresponding annual Tmax were summer AO values (the average of those in June, July and August), and the $\mathrm{AO}$ values corresponding annual Tmin were the winter $\mathrm{AO}$ values (the average of those in December, January and February) (Xue et al., 2012). Based on the Morlet wavelet, the cross wavelet transform between Tmax/Tmin and $\mathrm{AO}$ are conducted, and relevant results are shown in Figure 8 and Figure 9, respectively. The 95\% significance confidence level against red noise is exhibited as a thick contour, and the relative phase relationship is denoted as arrows (with anti-phase pointing left, in-phase pointing right). It can be found that Tmax has a no obvious positive relationship with AO in the URWB section in the entire period except for the period of 1966-1973 when a statistically significant anti-phase relationship with a 2 3 signal is detected. Similarly, Tmax has a no obvious positive relationship with AO in the MDWR section in 1958-1989, with significant correlations with 4-year signal during 1962-1969. However, a significant negative correlation is detected in 1966-1970. As for the Jing River basin, Tmax has a no obvious positive correlation with $\mathrm{AO}$ in the entire period. With regards to the Beiluo River basin, the correlations between Tmax and AO are dominated by significant linkages with a 5year signal during 1960-1966.
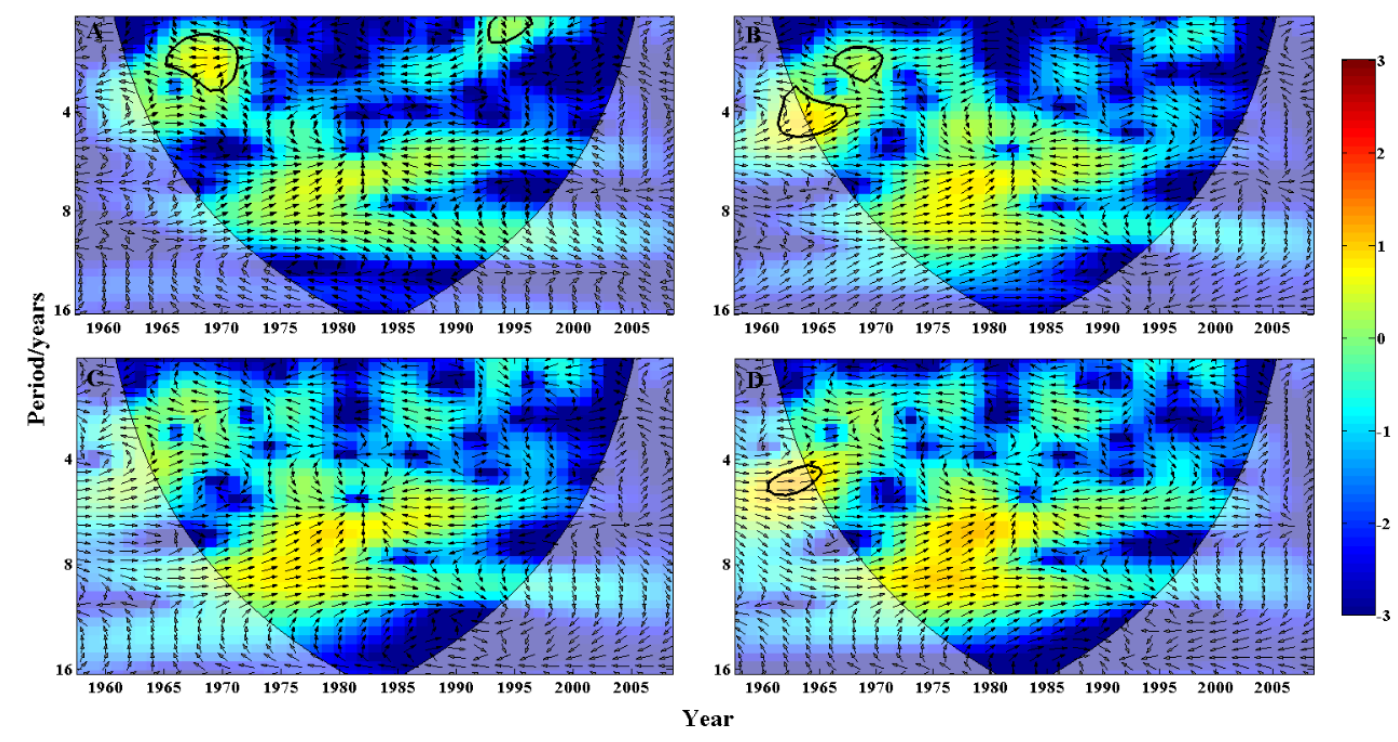

Figure 8. The cross wavelet transform between maximum temperature and AO. The $95 \%$ significance confidence level against red noise is exhibited as a thick contour, and the relative phase relationship is denoted as arrows (with anti-phase pointing left, in-phase pointing right).

$A, B, C$ and $D$ denote the URWB section, the MDWR section, the Jing River basin and the Beiluo River basin, respectively 

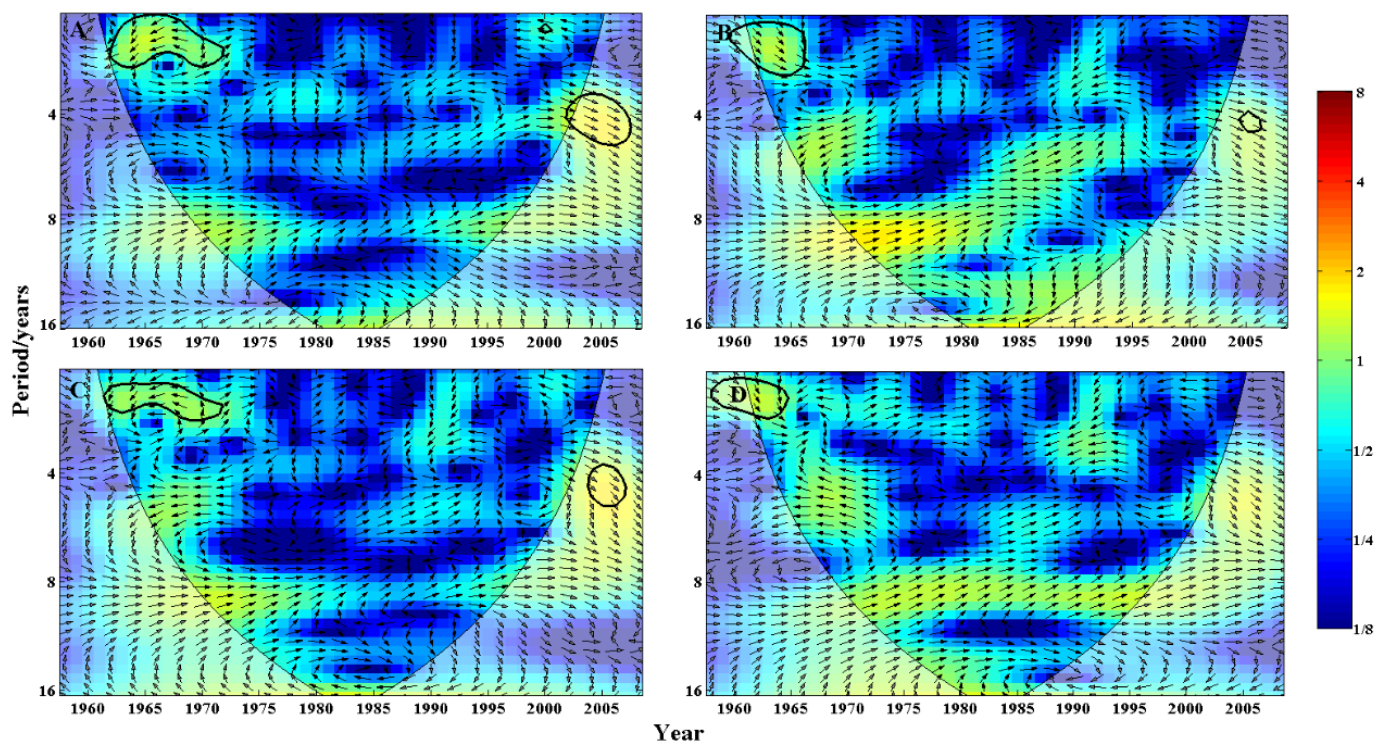

Figure 9. The cross wavelet transform between minimum temperature and AO. The 95\% significance confidence level against red noise is exhibited as a thick contour, and the relative phase relationship is denoted as arrows (with anti-phase pointing left, in-phase pointing right).

$A, B, C$ and D denote the URWB section, the MDWR section, the Jing River basin and the Beiluo River basin, respectively

As for the relations between Tmin and AO in the URWB section, the significantly positive relationship is found with a period of 4 years during 2000-2007, and a significantly negative relationship with AO is detected in 1960-1970 with a 1 2-year signal. Regarding the MDWR section, Tmin has a generally no obvious positive correlation with AO, but the relation become significant in 1960-1969 with a 1 2-year signal. As regards to the Jing River basin, the relationship between Tmin and AO is also dominated by positive correlations, and that in 2003-2006 is significant with a period of 4 years, whilst they have a significantly negative association in 1961-1973 with a 2-year signal. With regards to the Beiluo River basin, the relationship between Tmin and AO is also primarily dominated by positive linkages, and that in 1958-1966 is significant with a 1 2-year signal. Generally, the relations between Tmax/ Tmin and AO in the four subbasins have both similarity and difference. For example, both Figures $8 B$ and $8 D$ show that the Tmax has a strongly positive correlation with AO with the same 4 5-year signal during 1960 1965 in the MDWR section and the Beiluo River basin. In addition, both Figures $9 A$ and $9 C$ indicate that the Tmin has a strongly negatively relations with AO with the same 1 2-year signal during 1960 1970 and a significantly positive correlation with AO with the same 4 5-year signal in the URWR section and the Jing River basin. Through the comparison between Figure 8 and Figure 9, it can be roughly observed that the area enclosed by the thick contour in Figure 9 is larger than that in Figure 8, indicating that the correlation between Tmin and AO is stronger than that between Tmax and AO. Previous studies have reported that temperature extremes are modulated by the variability of precipitation (Liu et al., 2017), humidity (Krautgasser et al., 2015), wind speed (Jiménez-Hornero et al., 2011), and vegetation type (Migała et al., 2014) in addition to the anomaly of the large-scale atmospheric circulations. The combined effects of these factors may contribute to the different responses of temperature extremes to $\mathrm{AO}$ in the four sub-basins in the WRB. For example, Tabari et al. (2014) investigated the links 
between $\mathrm{AO}$ and inter-annual variability of Iranian evapotranspiration in 41 weather stations, and found that different stations had different characteristics in the response of evapotranspiration to AO. That is, the impacts of the large-scale circulation anomaly on local climatic variations may be different, especially for extreme events which is sensitive to climate change (Kapsomenakis et al., 2013; Zhao et al., 2019), depending on different climate types and underlying surface.

Furthermore, we selected the sub-basin 26 in the Yellow River Basin shown in Figure 1 which is near to the WRB (the sub-basin 31) in the Yellow River Basin (YRB) to conduct a similar analysis. The cross wavelet transform between annual Tmax/Tmin and summer/winter AO in the sub-basin 26 in the YRB are exhibited in Figure 10. It can be observed from Figure 10A that Tmax temperature shows a strongly positive correlation with AO with a signal of 4 6 year during 1959 1966 in sub-basin 26 in the YRB. The response is similar to that in the Beiluo River Basin in the WRB which is close to the subbasin 26 in the YRB. Importantly, it can be observed that a significantly positive relation is found between Tmax and AO with a signal of 2 3 year during 1975 1983 in the subbasin 26 , which is different from that in all the four sub-basins. The results further indicate that the relations between $\mathrm{AO}$ and Tmax would exhibit different features even in small areas in the WRB. Similar conclusions can be drawn for the relations between AO and Tmin as shown in Figure 10B.

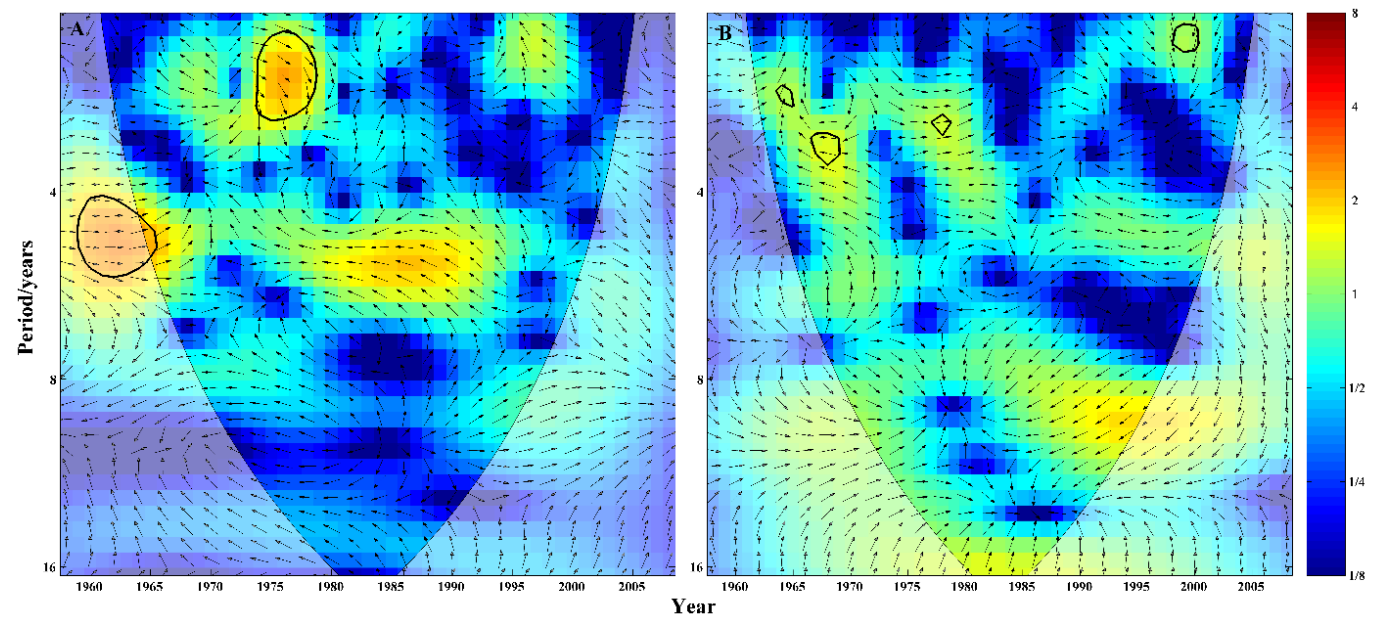

Figure 10. The cross wavelet transform between maximum (A)/ minimum (B) temperature and summer/winter AO in sub-basin 26 in the Yellow River Basin

In order to explore the response of temperature extremes to $\mathrm{AO}$ at different spatial scales, the correlations between Tmax/Tmin and AO in the whole WRB and YRB were obtained based on the cross wavelet analysis, and their cross wavelet transforms are shown in Figure 11. For the whole WRB, Tmax has a significantly negative correlation with AO with a signal of 2 3 year during 1965 1970 (Figure 11A), while Tmin exhibits a strongly positive correlation with AO with a signal of 4 5 year during 2002-2006 (Figure 11B). Regarding the whole YRB, Tmax has a strongly negative correlation with AO with a signal of 2 3 year during 1966 1980 and a significantly positive relation with AO with a signal of 4 6 year during 1959-1966 (Figure 11C), while Tmin exhibits a strongly positive association with AO with a signal of 2 3 year during 1965-1970 (Figure 11D). Therefore, the pattern of the correlations between temperature extremes and AO in the whole WRB has both 
similarity and difference compared with that in the whole YRB, but the difference is more obvious than its similarity. Generally, the URWB section in the WRB, the WRB, and the YRB has negative correlations between Tmax/Tmin and AO in 1965-1970. Differently, the WRB has significantly positive correlations between minimum temperature and $\mathrm{AO}$ in 2002-2007, whilst the YRB has significantly positive correlations between maximum temperature and AO in 1960-1965.
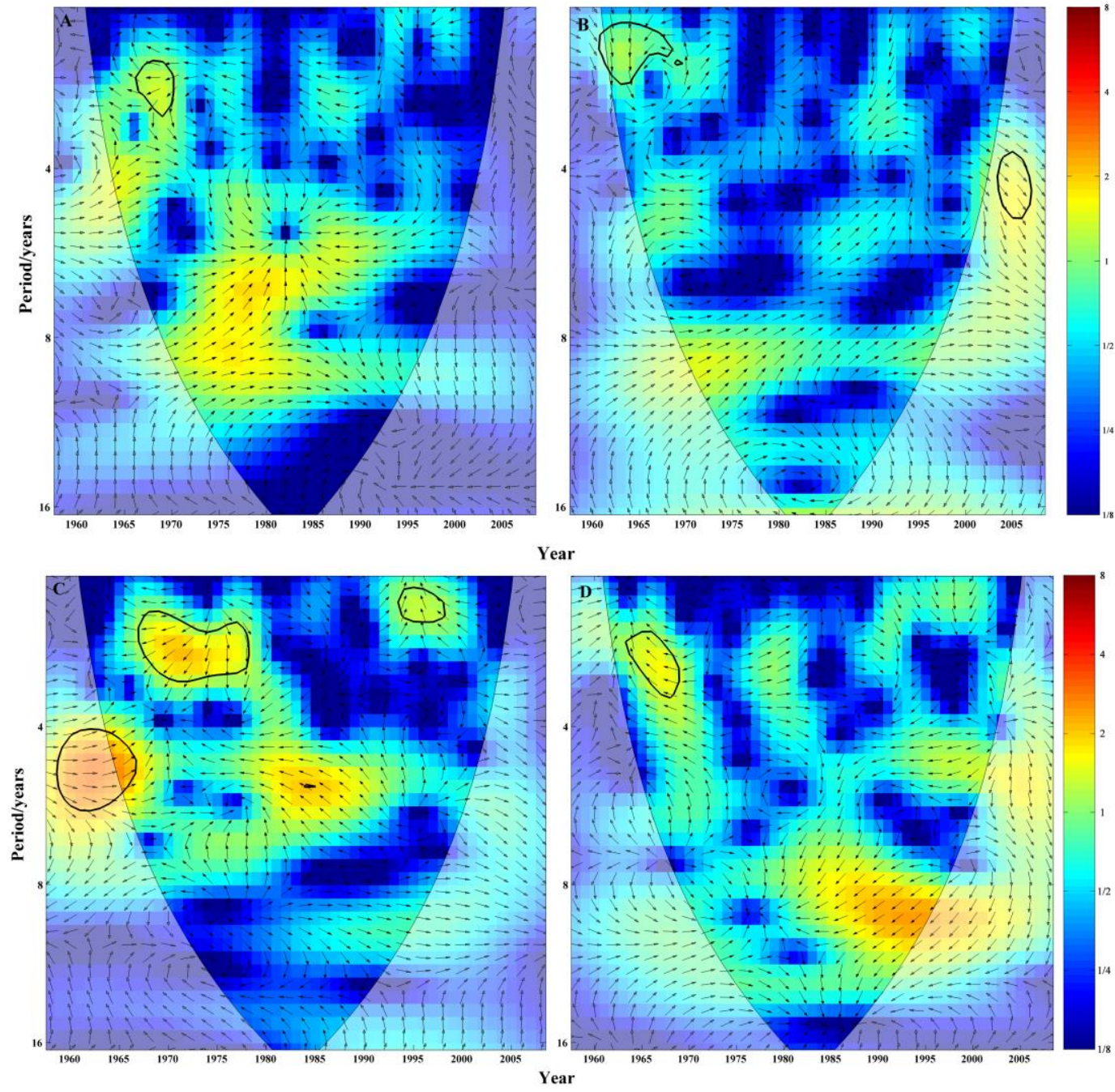

Figure 11. The cross wavelet transform between maximum (AC)/minimum (BD) temperature and summer/winter $A O$ in the whole Wei $(A B)$ and Yellow $(C D)$ River Basin

\section{Discussion}

Extreme climatic events frequently occur in the context of global warming, including extreme temperature and extreme precipitation events. In this study, the spatiotemporal variation characteristics of extreme temperature (Tmax/Tmin) are discussed, and it is found that the maximum and minimum temperature in WRB showed an increasing trend at different degrees. Liu et al. (2018b) found that the frequency of extreme temperature is increasing. In particular, station 17 is dominated by significant increasing trends in autumn and winter, while the summer is reversed. It is near to the monsoon zone than 
other meteorological stations, thus is impacted by climate change. However, increasing extreme temperatures will lead to a change of the temperature difference, which will have a serious impact on crops. Therefore, extreme temperature events should be given more attention.

It is found that $\mathrm{AO}$ is a possible factor influencing the extreme temperature changes in WRB. Similarly, AO also affect temperature changes in other areas (Zhong et al., 2017; Gao et al., 2019; Liu et al., 2019). Therefore, this study can provide a reference for other areas of high concern.

In addition, the present research focuses on the spatiotemporal variation of extreme temperatures, and tries to explain possible causes of the changes at different scales from the perspective of atmospheric circulation. Note that the spatiotemporal variation of extreme temperatures are also related to underlying surface conditions, human activities and carbon dioxide emissions. Therefore, future work should extend current research to reveal the effects of different factors on extreme temperature dynamics.

\section{Conclusion}

Changing characteristics of Tmax and Tmin in time and space across the WRB were thoroughly investigated in this study. The modified Mann-Kendall trend test method was applied to identify the change trends, and the heuristic segmentation method was used to identify possible change points of Tmax and Tmin at the monthly, seasonal, and annual scales. Additionally, the cross wavelet transform was utilized to reveal the correlation between annual Tmax and Tmin and AO to explore the possible cause of temperature extremes variations from the perspective of atmospheric circulation anomaly. The primary conclusions are presented as follows:

(1) The WRB is primarily characterized by increasing monthly Tmax especially in the western and middle basin, whilst monthly Tmin is found to decrease in the eastern basin in summer, but increase in winter. Similar pattern of changes in Tmin is found with significant increase in most months. The annual Tmax and Tmin in the WRB have an obviously increasing trend. As for the daily scale, most of stations show no obvious trends. The increasing Tmax and Tmin are expected to accelerate the rate of water circulation, thus resulting in high frequent extreme events such as droughts and floods, which will affect local ecosystem functions and agricultural production.

(2) The change points in monthly, seasonal, and annual Tmax and Tmin series were identified, and all of them have change points found. This suggests that the stationarity of the temperature extremes in the WRB has been invalid in 1958-2008.

(3) The Tmax has a strongly positive correlation with AO with 4 5-year signal during 1960-1965, whilst the Tmin has a strongly negatively relations with AO with the 1 2-year signal during 1960-1970 in the WRB. Overall, Tmax and Tmin have strong correlations with $\mathrm{AO}$, implying that the increasing temperature extremes in the WRB are closely related to the variation of $\mathrm{AO}$.

Acknowledgements. This study was jointly funded by the Open Research Fund of State Key Laboratory of Simulation and Regulation of Water Cycle in River Basin (China Institute of Water Resources and Hydropower Research, grant number IWHR-SKL-KF201803), the Key laboratory research projects of the education department of Shaanxi province (grant number 17JS104), the National Natural Science Foundation of China (grant number 51709221 and 51779203), the Key laboratory research projects of the education department of Shaanxi province (grant number 17JS104), the Planning Project of Science and 
Technology of Water Resources of Shaanxi (grant numbers 2015slkj-27 and 2017slkj-19), and the Belt and Road Special Foundation of the State Key Laboratory of Hydrology-Water Resources and Hydraulic Engineering (2018490711).

\section{REFERENCES}

[1] Beniston, M., Stephenson, D. B. (2004): Extreme climatic events and their evolution under changing climatic conditions. - Global Planet. Change 44(1): 1-9.

[2] Bonsal, B. R., Zhang, X., Vincent, L. A. (2001): Characteristics of daily extreme temperatures over Canada. - J. Climate 14: 1959-1976.

[3] China Meteorological Administration. (2006): Climate and Environment in China. Meteorology Press, Beijing. (in Chinese).

[4] Dai, M., Huang, S., Z., Huang, Q., Leng, G. Y., Guo, Y., Wang, L., Fang, W., Li, P., Zheng, X.D. (2020): Assessing agricultural drought risk and its dynamic evolution characteristics. - Agricultural Water Management 231: 106003.

[5] Daufresne, M., Lengfellner, K., Sommer, U. (2009): Global warming benefits the small in aquatic ecosystems. - Proceedings of the National Academy of Sciences USA 106(31): 12788-12793.

[6] Easterling, D. R., Meehl, G. A., Parmesan, C., Changnon, S. A., Karl, T. R., Mearns, L. O. (2000a): Climate extremes: observations, modeling, and impacts. - Science 289(5487): 2068-2074.

[7] Easterling, D. R., Evans, J. L., Groisman, P. Y., Karl, T. R., Kunkel, K. E., Ambenje, P. (2000b): Observed variability and trends in extreme climate events. - Bull Am. Meteorol. Soc. 81: 417-425.

[8] Fang, W., Huang, S. Z., Ren, K., Huang, Q., Huang, G. H., Cheng, G. H., Li, K. L. (2019a): Examining the applicability of different sampling techniques in the development of decomposition-based streamflow forecasting models. - Journal of Hydrology 568: 534550 .

[9] Fang, W., Huang, S. Z., Huang, Q., Huang, G. H., Wang, H., Leng, G. Y., Wang, L., Guo, Y. (2019b): Probabilistic assessment of remote sensing-based terrestrial vegetation vulnerability to drought stress of the Loess Plateau in China. - Remote Sensing of Environment, 232: 111290.

[10] Fuhrer, J., Beniston, M., Fischlin, A., Frei, C., Goyette, S., Jasper, K., Pfister, C. (2006): Climate Risks and Their Impact on Agriculture and Forests in Switzerland. - Climatic Change 79(1): 79-102.

[11] Gao, M., Yang, Y., Shi, H., Gao, Z. (2019): SOM-based synoptic analysis of atmospheric circulation patterns and temperature anomalies in China. - Atmospheric Research 220: 4656.

[12] Gilroy, K. L., McCuen, R. H. (2012): A nonstationary flood frequency analysis method to adjust for future climate change and urbanization. - J. Hydrol. 414-415: 40-48.

[13] Guo, J. L., Guo, S. L., Li, Y., Chen, H., Li, T. Y. (2013): Spatial and temporal variation of extreme precipitation indices in the Yangtze River basin, China. - Stoch. Environ. Res. Risk Assess. 27: 459-475.

[14] Guo, Y., Huang, S. Z., Huang, Q., Wang, H., Fang, W., Yang, Y. Y., Wang, L. (2019a): Assessing socioeconomic drought based on an improved Multivariate Standardized Reliability and Resilience Index. - Journal of Hydrology 568: 904-918.

[15] Guo, Y., Huang, S. Z., Huang, Q., Wang, H., Wang, L., Fang, W. (2019b): Copulas-based bivariate socioeconomic drought dynamic risk assessment in a changing environment. Journal of Hydrology 575: 1052-1064.

[16] Guo Y., Huang S., Huang Q., Leng G., Fang W., Wang L., Wang H. (2020): Propagation thresholds of meteorological drought for triggering hydrological drought at various levels. - Sci. Total Environ. 712: 136502. 
[17] Hamed, K. H., Rao, A. R. (1998): A modified Mann-Kendall trend test for autocorrelated data. - J Hydrol. 204: 182-196.

[18] Han, Z. M., Huang, S. Z., Huang, Q., Leng, G. Y., Wang, H., He, L., Fang, W., Li, P. (2019): Assessing GRACE-based terrestrial water storage anomalies dynamics at multitimescales and their correlations with teleconnection factors in Yunnan Province, China. Journal of Hydrology 574: 836-850.

[19] Huang, S. Z., Chang, J. X., Huang, Q., Chen, Y. T. (2014a): Monthly streamflow prediction using modified EMD-based support vector machine. - Journal of Hydrology 511: 764-775.

[20] Huang, S. Z., Chang, J. X., Huang, Q., Chen, Y. T. (2014b): Spatio-temporal changes and frequency analysis of drought in the Wei River Basin, China. - Water Resour. Manag. 28(10): 3095-3110.

[21] Huang, S. Z., Hou, B. B., Chang, J. X., Huang, Q., Chen, Y. T. (2014c): Copulas-based probabilistic characterization of the combination of dry and wet conditions in the Guanzhong Plain, China. - J. Hydrol. 519: 3204-3213.

[22] Huang, S. Z., Huang, Q., Chang, J. X., Leng, G. Y. (2016): Linkages between hydrological drought, climate indices and human activities: a case study in the Columbia River basin. International Journal of climatology 36(1): 280-290.

[23] Huang, S. Z., Li, P., Huang, Q., Leng, G. Y., Hou, B. B., Ma, L. (2017): The propagation from meteorological to hydrological drought and its potential influence factors. - Journal of Hydrology 547: 184-195.

[24] Huang, S. Z., Zheng, X. D., Ma, L., Wang, H., Huang, Q., Leng, G. Y., Meng, E., Guo, Y. (2020): Quantitative contribution of climate change and human activities to vegetation cover variations based on GA-SVM model. - Journal of Hydrology 584: 124687.

[25] Hudgins, L., Friehe, C. A., Mayer, M. E. (1993): Wavelet transforms and atmospheric turbulence. - Phys. Rev. Lett. 71: 3279-3282.

[26] Hudgins, L., Huang, J. P. (1996): Bivariate Wavelet Analysis of Asia Monsoon and ENSO. - Adv. Atmos. Sci. 13(3): 299-312.

[27] IPCC. (2007): Summary for Policymakers of Climate Change 2007: the Physical Science Basis. - Contribution of Working Group I to the Fourth Assessment Report of the Intergovernmental Panel on Climate Change.

[28] IPCC. (2013): Summary for Policymakers of Climate Change 2013: the Physical Science Basis. - Contribution of Working Group I to the Fifth Assessment Report of the Intergovernmental Panel on Climate Change.

[29] Jiménez-Hornero, F. J., Pavón-Domínguez, P., Gutiérrez de Ravé, E., Ariza-Villaverde, A. B. (2011): Joint multifractal description of the relationship between wind patterns and land surface air temperature. - Atmos. Res. 99: 366-376.

[30] Kapsomenakis, J., Kolokotsa, D., Nikolaou, T., Santamouris, M., Zerefos, S. C. (2013): Forty years increase of the air ambient temperature in Greece: the impact on buildings. Energ. Convers. Manage. 74: 353-365.

[31] Krautgasser, C., Danzer, R., Supancic, P., Bermejo, R. (2015): Influence of temperature and humidity on the strength of low temperature co-fired ceramics. - J. Eur. Ceram. Soc. 35: 1823-1830.

[32] Kunkel, K. E., Pritke, R. A., Changnon, S. A. (1999): Temporal fluctuation in weather and climate extremes that cause economic and human health impacts-a review. - Bull Am. Meteorol. Soc. 80: 1077-1098.

[33] Lehner, B., Döll, P., Alcamo, J., Henrichs, T., Kaspar, F. (2006): Estimating the impact of global change on flood and drought risks in Europe: a continental, integrated analysis. Climatic Change 75(3): 273-299.

[34] Leng, G., Tang, Q., Huang, M., Hong, Y., Leung, L. R. (2015a): Projected changes in mean and interannual variability of surface water over continental China. - Sci. China Earth Sci. 58(5): 739-754.

[35] Leng, G., Tang, Q., Rayburg, S. (2015b): Climate change impacts on meteorological, agricultural and hydrological droughts in China. - Glob. Planet. Change 126: 23-34. 
[36] Leng, G., Tang, Q., Huang, S., Zhang, X. (2015c): Extreme hot summers in China in the CMIP5 climate models. - Clim. Change 135: 669-681.

[37] Liang, K., Bai, P., Li, J. J., Liu, C. M. (2014): Variability of temperature extremes in the Yellow River basin during 1961-2011. - Quatern. Int. 336: 52-64.

[38] Liu, S. Y., Huang, S. Z., Huang, Q., Xie, Y. Y., Leng, G. Y., Luan, J. K., Song, X. Y., Wei, X., Li, X. Y. (2017): Identification of the non-stationarity of extreme precipitation events and correlations with large-scale ocean-atmospheric circulation patterns: A case study in the Wei River Basin, China. - Journal of Hydrology 548: 184-195.

[39] Liu, S. Y., Huang, S. Z., Xie, Y. Y., Leng, G. Y., Huang, Q., Wang, L., Xue, Q. (2018a): Spatial-temporal changes of rainfall erosivity in the loess plateau, China: Changing patterns, causes and implications. - Catena 166: 279-289.

[40] Liu, S. Y., Huang, S. Z., Xie, Y. Y., Huang, Q., Leng, G. Y., Hou, B. B., Zhang, Y., Wei, X. (2018b): Spatial-temporal changes of maximum and minimum temperatures in the Wei River Basin, China: Changing patterns, causes and implications. - Atmospheric research 204: 1-11.

[41] Liu, S. Y., Huang, S. Z., Xie, Y. Y., Huang, Q., Wang, H., Leng, G. Y. (2019): Assessing the non-stationarity of low flows and their scale-dependent relationships with climate and human forcing. - Science of the Total Environment 687: 244-256.

[42] Liu, X., Xu, Z., Peng, D., Wu, G. (2019): Influences of the North Atlantic Oscillation on extreme temperature during the cold period in China. - International Journal of Climatology 39(1): 43-49.

[43] Li, Z. Y., Huang, S. Z., Liu, D. F., Leng, G. Y., Zhou, S., Huang, Q. (2020): Assessing the effects of climate change and human activities on runoff variations from a seasonal perspective. Stochastic Environmental Research and Risk Assessment, in press. DOI: 10.1007/s00477-020-01785-1

[44] Menzel, L., Bürger, G. (2002): Climate change scenarios and runoff response in the Mulde catchment (Southern Elbe, Germany). - J. Hydrol. 267: 53-64.

[45] Migała, K., Wojtuń, B., Szymański, W., Muskała, P. (2014): Soil moisture and temperature variation under different types of tundra vegetation during the growing season: A case study from the Fuglebekken catchment, SW Spitsbergen. - Catena 116: 10-18.

[46] Milly, P. C. D., Betancourt, J., Falkenmark, M., Hirsch, R. M., Kundzewicz, Z. W., Lettenmaier, D. P., Stouffer, R. J. (2008): Stationarity is dead: Whither water management? - Science 319: 573-574.

[47] Nasrallah, H. A., Nieplova, E., Ramadan, E. (2004): Warm season extreme temperature events in Kuwait. - J. Arid Environ. 56: 357-371.

[48] Patz, J. A., Campbell-Lendrum, D., Holloway, T., Foley, J. A. (2005): Impact of regional climate change on human health. - Nature 438(7066): 310-317.

[49] Pedro, B. G., Plamen, C. I., Luís, A. N. A. (2001): Scale invariance in the nonstationarty of human heart rate. - Phys. Rev. Lett. 87(16): 160815.

[50] Pereira, J., Figueiredo, N., Goufo, P., Carneiro, J., Morais, R., Carranca, C., Coutinho, J., Trindade, H. (2013): Effects of elevated temperature and atmospheric carbon dioxide concentration on the emissions of methane and nitrous oxide from Portuguese flooded rice fields. - Atmos. Environ. 80: 464-471.

[51] Piao, S., Ciais, P., Huang, Y., Huang, Y., Shen, Z., Peng, S., Li, J., Zhou, L., Liu, H., Ma, Y., Ding, Y., Friedingstei, P., Liu, C., Tan, K., Yu, Y., Zhang, T., Fang, J. (2010): The impacts of climate change on water resources and agriculture in China. - Nature 467(7311): 43-51.

[52] Ren, K., Huang, S. Z., Huang, Q., Wang, H., Leng, G.Y., Fang, W., Li, P. (2019): Assessing the reliability, resilience, and vulnerability of water supply system under multiple uncertain sources. - Journal of Cleaner Production 252: 119806.

[53] Sheffield, J., Wood, E. F., Roderick, M. L. (2012): Little change in global drought over the past 60 years. - Nature 491: 435-438. 
[54] Tabari, H., Talaee, P. H., Willems, P. (2014): Links between Arctic Oscillation (AO) and inter-annual variability of Iranian evapotranspiration. - Quaternary International 345: 148157.

[55] Toreti, A., Xoplaki, E., Maraun, D., Kuglitsch, K. G., Wanner, H., Luterbacher, J. (2010): Characterisation of extreme winter precipitation in Mediterranean coastal sites and associated anomalous atmospheric circulation patterns. - Nat. Hazard. Earth Sys. 10: 10371050.

[56] Torrence, C., Compo, G. P. (1998): A Practical Guide to Wavelet Analysis. - Bull. Am. Meteorol. Soc. 79(1): 61-78.

[57] Tudesquea, L., Tisseuila, C., Leka, S. (2014): Scale-dependent effects of land cover on water physico-chemistry and diatom-based metrics in a major river system, the AdourGaronne basin (South Western France). - Sci Total Environ. 466-467: 47-55.

[58] Vogel, R. M., Yaindl, C., Walter, M. (2011): Nonstationarity: flood magnification and recurrence reduction factors in the United States. - J. Am. Water Resour As. 47(3): 464474.

[59] Wang, S. J., Zhang, M. J., Sun, M. P., Wang, B. L., Li, X. F. (2013): Changes in precipitation extremes in alpine areas of the Chinese Tianshan Mountains, central Asia, 1961-2011. - Quatern. Int. 311: 97-107.

[60] Wang, W. G., Shao, Q. X., Yang, T., Peng, S., Yu, Z., Taylor, J., Xing, W., Zhao, C., Sun, F. (2013): Changes in daily temperature and precipitation extremes in the Yellow River Basin, China. - Stoch. Env. Res. Risk A. 27(2): 401-421.

[61] World Meteorological Organization. (2003): Statement on the Status of Global Climate in 2003. - WMO, Geneva, Switzerland. Publication No. 966.

[62] Xue, H. X., Meng, D., Wu, D. L., Wang, L. X., Li, Q. (2012): Extreme temperature threshold changes and its association with AO index in Ningxia Hui Autonomous Region of China in 1959-2009. - Scientia Geographica Sinica 32(3): 380-385. (in Chinese).

[63] Yu, Z., Li, X. L. (2015): Recent trends in daily temperature extremes over northeastern China (1960-2011). - Quatern. Int. 380-381: 35-48.

[64] Zhang, H., Chen, Y., Ren, G. (2008): The characteristics of precipitation variation of Weihe River Basin in Shaanxi Province during recent 50 years. - Agricultural Research in the Arid Areas 26(4): 236-242. (In Chinese).

[65] Zhao, J., Huang, S. Z., Huang, Q., Wang, H., Leng, G. Y., Peng, J., Dong, H. X. (2019): Copula-Based Abrupt Variations Detection in the Relationship of Seasonal VegetationClimate in the Jing River Basin, China. - Remote Sensing 11: 1628.

[66] Zhao, J., Huang, S. Z., Huang, Q., Leng, G. Y., Wang H., Li, P. (2020a): Watershed waterenergy balance dynamics and their association with diverse influencing factors at multiple time scales. - Sci. Total Environ. 711: 135189.

[67] Zhao, J., Huang, S. Z., Huang, Q., Wang, H., Leng, G. Y., Fang, W. (2020b): Time-lagged response of vegetation dynamics to climatic and teleconnection factors. - Catena 189: 104474.

[68] Zhao, M. L., Huang, S. Z., Huang, Q., Wang, H., Leng, G. Y., Xie, Y. Y. (2019a): Assessing socio-economic drought evolution characteristics and their possible meteorological driving force. - Geomatics, Natural Hazard and Risk 10(1): 1084-1101.

[69] Zhao, M. L., Huang, S. Z., Huang, Q., Wang, H., Leng, G. Y., Liu, S. Y., Wang, L. (2019b): Copula-Based Research on the Multi-Objective Competition Mechanism in Cascade Reservoirs Optimal Operation. - Water 11: 995.

[70] Zhong, K., Zheng, F., Wu, H., Qin, C., Xu, X. (2017): Dynamic changes in temperature extremes and their association with atmospheric circulation patterns in the Songhua River Basin, China. - Atmospheric research 190: 77-88. 